\title{
The effect of prior statin use on 30-day mortality for patients hospitalized with community-acquired pneumonia Eric M Mortensen ${ }^{* 1,2}$, Marcos I Restrepo ${ }^{1,3}$, Antonio Anzueto ${ }^{3}$ and Jacqueline Pugh ${ }^{1,3}$
}

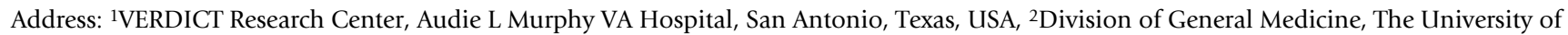
Texas Health Science Center at San Antonio, USA and ${ }^{3}$ Division of Pulmonary and Critical Care Medicine, The University of Texas Health Science Center at San Antonio, USA

Email: Eric M Mortensen* - mortensen@verdict.uthscsa.edu; Marcos I Restrepo - mrestrepo@verdict.uthscsa.edu; Antonio Anzueto - anzueto@uthscsa.edu; Jacqueline Pugh - jpugh@verdict.uthscsa.edu

* Corresponding author

Published: 25 July 2005

Respiratory Research 2005, 6:82 doi:10.1 186/1465-992I-6-82
Received: 26 April 2005

Accepted: 25 July 2005

This article is available from: http://respiratory-research.com/content/6/1/82

(c) 2005 Mortensen et al; licensee BioMed Central Ltd.

This is an Open Access article distributed under the terms of the Creative Commons Attribution License (http://creativecommons.org/licenses/by/2.0), which permits unrestricted use, distribution, and reproduction in any medium, provided the original work is properly cited.

\begin{abstract}
Background: Recent studies suggest that HMG-CoA reductase inhibitors ("statins") may have beneficial effects for patients at risk for some types of infections. We examined the effect of prior outpatient use of statins on mortality for patients hospitalized with community-acquired pneumonia.
\end{abstract}

Methods: A retrospective cohort study conducted at two tertiary teaching hospitals. Eligible subjects were admitted with a diagnosis of, had a chest $\mathrm{x}$-ray consistent with, and had a discharge ICD-9 diagnosis of pneumonia. Subjects were excluded if they were "comfort measures only" or transferred from another acute care hospital. Subjects were considered to be on a medication if they were taking it at the time of presentation.

Results: Data was abstracted on 787 subjects at the two hospitals. Mortality was $9.2 \%$ at 30 -days and $13.6 \%$ at 90 -days. At presentation $52 \%$ of subjects were low risk, $34 \%$ were moderate risk, and $14 \%$ were high risk based on the pneumonia severity index. In the multivariable regression analysis, after adjusting for potential confounders including a propensity score, the use of statins at presentation (odds ratio $0.36,95 \%$ confidence interval $0.14-0.92$ ) was associated with decreased 30-day mortality.

Discussion: Prior outpatient statin use was associated with decreased mortality in patients hospitalized with community-acquired pneumonia despite their use being associated with comorbid illnesses likely to contribute to increased mortality. Confirmatory studies are needed, as well as research to determine the mechanism(s) of this protective effect.

\section{Background}

Community-acquired pneumonia is the seventh leading cause of death and the leading cause of infectious death in the United States [1]. Although mortality due to commu- nity-acquired pneumonia decreased significantly with the introduction of antibiotics in the 1950s, since that time mortality has been stable or increasing [2]. Despite this, only a few new classes of antibiotics have been added to 
the armamentarium for treating community-acquired pneumonia in the last 20 years and no new classes of medications beyond antibiotics have been added since the 1950s.

Recent studies have demonstrated that inhibitors of HMG-CoA reductase ("statins") have significant immunomodulatory effects and reduce systemic cytokine levels [3-8]. These cytokines play an important role in host defense mechanisms for patients with communityacquired pneumonia but under certain conditions may lead to septic shock or acute respiratory distress syndrome (ARDS) [9-11]. Recent studies have demonstrated that in patients hospitalized with bacteremia or diabetic lower extremity infections those patients who were taking statins had a significantly decreased odds of death after adjusting for other potential confounders $[12,13]$.

The study aim was to assess the effects of prior outpatient statin use on 30-day mortality for patients hospitalized with community-acquired pneumonia after adjusting for other potential confounders including a propensity score based upon the use/non-use of statins at presentation.

\section{Methods}

This a retrospective cohort study of patients hospitalized with community-acquired pneumonia at 2 academic tertiary care hospitals in San Antonio, Texas. Both hospitals are teaching affiliates of the University of Texas Health Science Center at San Antonio. The Institutional Review Board of the University Health Science Center at San Antonio approved the research protocol with exempt status.

\section{Study Sites/Inclusion and Exclusion Criteria}

We identified all patients admitted to the study hospitals between January 1, 1999 and December 1, 2002 with a primary discharge diagnosis of pneumonia (ICD-9 codes $480.0-483.99$ or 485-487.0) or secondary discharge diagnosis of pneumonia with a primary diagnosis of respiratory failure (518.81) or sepsis (038.xx). Subjects were included if they were 1) greater than 18 years of age, 2) had an admission diagnosis of community-acquired pneumonia, and 3) had a radiographically confirmed infiltrate or other finding consistent with communityacquired pneumonia on chest x-ray or CT obtained within 24 hours of admission.

Exclusion criteria included 1) having been discharged from an acute care facility within 14 days of admission, 2) transfer after being admitted to another acute care hospital, and 3) being comfort measures only on this admission. If a subject was admitted more than once during the study period, only the first hospitalization was abstracted.

\section{Data Abstraction}

Chart review data included: demographics, comorbid conditions, physical examination findings, laboratory data, and chest radiograph reports. In addition, data on important processes of care measures for patients hospitalized with community-acquired pneumonia were also abstracted: first dose of antibiotics within 4 hours and 8 hours of admission, collection of blood cultures prior to antibiotic administration, and obtaining blood cultures and oxygen saturation measurement within 24 hours of presentation [14]. Antimicrobial therapy was considered guideline-concordant if it agreed with either the 2000 Infectious Diseases Society of America or 2001 American Thoracic Society guidelines $[15,16]$. Information on all outpatient medications that were either 1) reported as currently being taken by the patient at presentation, or 2) listed in the electronic medical record, were recorded. Patients were defined as taking a statin if they had a statin listed on the electronic medical record (as an outpatient medication) or history and physical under outpatient medications.

Mortality was assessed using information from the Texas Department of Health and Department of Veteran Affairs clinical database. Mortality status was assessed through December 2002.

\section{Risk Adjustment}

The pneumonia severity index score was used to assess severity of illness at presentation [17]. The pneumonia severity index is a validated prediction rule for 30-day mortality in patients with community-acquired pneumonia. This rule is based on three demographic characteristics, five comorbid illnesses, five physical examination findings, and seven laboratory and radiographic findings from the time of presentation. Patients are classified into five risk classes with 30-day mortality ranging from $0.1 \%$ for class I to $27 \%$ for class $\mathrm{V}$ for patients enrolled in the PORT cohort study [17].

\section{Outcome}

We used 30-day mortality as the outcome for this study. Previous research has demonstrated that 30-day mortality is primarily due to the community-acquired pneumonia rather than other co-existing co-morbid conditions $[18,19]$. Therefore by using 30-day mortality as our outcome we are able to minimize the effect of statin use on other co-morbid conditions.

\section{Sample Size}

Sample size calculations were based on an assumption of a $30 \%$ overall utilization of statins and a $40 \%$ difference in use between those who died and survived. We calculated that 800 subjects were needed to have an $80 \%$ 
probability to detect a significant mortality difference at 30 -days (with an $\alpha$ of 0.05 and $\beta$ of 0.20 ).

\section{Statistical Analyses}

Univariate statistics were used to test the association of sociodemographic and clinical characteristics with allcause 30-day mortality. Categorical variables were analyzed using the Chi-square test and continuous variables were analyzed using Student's t-test.

A propensity score technique was used to balance covariates associated with statin use between groups [20]. The use of the propensity score technique provides a way, in non-randomized studies, to control for pretreatment differences by defining sets of comparable patients. The propensity score was derived from a logistic regression model. A dichotomous indicator variable indexing whether a patient was on a statin was our response variable. The covariates used in the propensity score model were the pneumonia severity index score (which includes comorbid conditions such as congestive heart failure, liver disease, and history of stroke), history of alcoholism, history of diabetes mellitus, coronary artery disease, and current tobacco use. Variables were entered, and maintained, in the model if they had a p-value $<0.20$ in the univariate analysis (with statin use as the dependent variable) and had a p-value $<0.20$ in the final model.

We used a Cox proportional hazard model to estimate, and graph, the baseline survivor functions after adjusting for the propensity score and processes of care including use of guideline-concordant antibiotics, initial dose of antibiotics within 4 hours, obtaining blood cultures prior to antibiotics and within 24 hours, and assessing oxygenation at presentation.

A multivariable logistic regression model was derived with 30-day mortality as the dependent variable, and the propensity score, use of statin at presentation, and process of care measures (initial antibiotics within 4 hours and obtaining blood cultures prior to initial dose of antibiotics, and whether antimicrobial therapy was guideline concordant) as potential confounding variables. Interactions were assessed using cross-product terms between the medications and all of the other variables retained in the models. No significant interactions terms were noted, so they were excluded from the final models. All analyses were performed using STATA version 8 (Stata Corporation, College Station, Texas).

\section{Results}

Data was abstracted on 787 patients at the two hospitals. The mean age was 60 years with a standard deviation of 16 years. The population was $79 \%$ male, $84 \%$ were admitted through the emergency department, and 20\% were admit- ted to the intensive care unit (ICU) within the first 24 hours after admission. Mortality was $9.2 \%$ at 30 -days and $13.6 \%$ at 90 -days. By pneumonia severity index, 52\% were low risk (pneumonia severity index classes I-III), $34 \%$ were moderate risk (pneumonia severity index class IV), and $14 \%$ were high risk (pneumonia severity index class V). Regarding community-acquired pneumoniarelated processes of care, $28 \%$ received the initial dose of antibiotics within 4 hours of presentation and an additional 22\% received the initial antibiotic dose within 8 hours, $76 \%$ of patients had blood cultures obtained within 24 hours and prior to antibiotics, and oxygenation was assessed at presentation in $91 \%$.

Table 1 shows the demographic factors, clinical characteristics, and processes of care data for this population by 30day mortality. In the univariate analysis numerous individual components of the PSI were significantly associated with 30-day mortality including age, nursing home residency, history of congestive heart failure, history of malignancy, altered mental status, systolic blood pressure $<90 \mathrm{mmHg}$, tachycardia> 125 beats per minute, arterial acidosis, elevated blood urea nitrogen $30 \mathrm{mg} / \mathrm{dl}$, serum sodium $<130 \mathrm{meq} / \mathrm{l}$, and pleural effusion on chest radiograph. The only processes of care that were statistically significant were the assessment of oxygenation within 24 hours or presentation and use of guideline-concordant antibiotics. Statin use had only a borderline significance $(\mathrm{p}=0.07)$ in the univariate analysis.

Of the 787 subjects, 110 subjects (14\%) were on statins at presentation. Table 2 demonstrates the association between clinical and demographic variables and the use/ non-use of statins. Components of the PSI that were significantly associated with statin use include increased age, history of congestive heart failure, history of stroke, systolic blood pressure < $90 \mathrm{mmHG}$, and an elevated serum glucose. History of diabetes mellitus was also associated with statin use. Conditions inversely associated with statin use include: nursing home residence, history of alcoholism, chronic liver disease, current tobacco use, and pleural effusion on chest $\mathrm{x}$-ray. Figure 1 displays the \% survival by statin-use versus non-use over 30-days after adjusting for the propensity score and processes of care, showing that statin use is associated with higher survival at 30-days ( $\mathrm{p}=0.001)$.

In the multivariable regression analysis, after adjusting for the propensity score and processes of care, the use of statins at presentation (odds ratio 0.36, 95\% confidence interval 0.14-0.92) was significantly associated with decreased 30-day mortality. 
Table I: Subject Demographic and Clinical Characteristics by 30-Day Mortality*

\begin{tabular}{|c|c|c|c|}
\hline \multirow[t]{2}{*}{ Variable } & \multicolumn{2}{|c|}{ 30-Day Mortality } & \multirow[b]{2}{*}{ p-valzue } \\
\hline & Alive $(n=7 \mid 5)$ & Dead $(n=72)$ & \\
\hline Age, years $+/$ - standard deviation & $60.2+/-16.4$ & $62.9+/-16.4$ & 0.09 \\
\hline Men & $56 \mid(79)$ & $60(83)$ & 0.3 \\
\hline Nursing home resident & $4 I(6)$ & $13(18)$ & $<0.001$ \\
\hline Admitted through emergency department & $598(84)$ & $58(8 I)$ & 0.5 \\
\hline Admitted to intensive care within 24 hours & $118(17)$ & $36(50)$ & $<0.001$ \\
\hline \multicolumn{4}{|l|}{ Preexisting Comorbid Conditions } \\
\hline Congestive heart failure & $105(15)$ & $18(25)$ & 0.02 \\
\hline Chronic pulmonary disease & $195(27)$ & $23(31)$ & 0.4 \\
\hline History of stroke & $93(13)$ & $12(17)$ & 0.4 \\
\hline Chronic liver disease & $83(12)$ & $11(15)$ & 0.4 \\
\hline History of malignancy & $58(8)$ & $20(28)$ & $<0.001$ \\
\hline Renal insufficiency & $74(10)$ & $13(18)$ & 0.05 \\
\hline \multicolumn{4}{|c|}{ History, Physical, Laboratory, and Radiographic Data } \\
\hline Altered mental status & $68(10)$ & $17(24)$ & $<0.001$ \\
\hline Respiratory rate $>30$ per minute & $71(10)$ & $11(15)$ & 0.2 \\
\hline Systolic blood pressure $<90 \mathrm{mmHg}$ & $16(2)$ & $5(7)$ & 0.02 \\
\hline Heart rate $>125$ per minute & $86(12)$ & $19(26)$ & 0.001 \\
\hline Temperature $<95^{\circ}$ or $>104^{\circ} \mathrm{F}$ & $19(3)$ & $2(3)$ & 0.9 \\
\hline Arterial $\mathrm{pH}<7.35$ & $37(5)$ & $12(17)$ & $<0.001$ \\
\hline Arterial oxygenation saturation $<90 \%$ & $149(21)$ & $27(38)$ & 0.001 \\
\hline Hematocrit $<30 \%$ & $64(9)$ & $8(11)$ & 0.5 \\
\hline Serum blood urea nitrogen $>30 \mathrm{mg} / \mathrm{dL}$ & 135 (19) & $33(46)$ & $<0.001$ \\
\hline Serum glucose $>250 \mathrm{mg} / \mathrm{dL}$ & $71(10)$ & $5(7)$ & 0.4 \\
\hline Serum sodium $<130 \mathrm{meq} / \mathrm{L}$ & $98(14)$ & $18(25)$ & 0.01 \\
\hline Pleural effusion on chest radiograph & $160(11)$ & $29(35)$ & 0.001 \\
\hline \multicolumn{4}{|l|}{ Pneumonia Severity Index } \\
\hline Class I-III & $393(54)$ & $16(22)$ & \\
\hline Class IV & $240(34)$ & $26(36)$ & \\
\hline Class $\mathrm{V}$ & $82(12)$ & $30(42)$ & $<0.001$ \\
\hline \multicolumn{4}{|l|}{ Processes of Care } \\
\hline Initial antibiotics within 4 hours & $20 \mathrm{I}(28)$ & $22(31)$ & 0.7 \\
\hline Initial antibiotics within 8 hours & $358(50)$ & $36(50)$ & 1.0 \\
\hline Blood cultures prior to antibiotics & $540(76)$ & $55(76)$ & 0.9 \\
\hline Oxygenation assessed $\leq 24$ hours & $538(75)$ & $65(90)$ & 0.004 \\
\hline Guideline-concordant antibiotics used & $574(80)$ & $5 I(7 I)$ & 0.05 \\
\hline \multicolumn{4}{|l|}{ Outpatient Medications } \\
\hline Statin & $105(15)$ & $5(7)$ & 0.07 \\
\hline
\end{tabular}

* Data are presented as number (\%) or mean +/-standard deviation

\section{Discussion}

We found that prior outpatient use of statins was associated with decreased 30-day mortality for subjects hospitalized with community-acquired pneumonia. Our findings provide further support to previous work that demonstrate that statin use is associated with decreased mortality for patients with acute bacterial illnesses $[12,13]$. Further studies are needed to examine the impact of statins, both pre-hospitalization and acute, on patients hospitalized with community-acquired pneumonia and other bacterial illnesses.

Our study, with a methodologically stronger cohort design, supports the findings of the recent case-control study which demonstrated that patients hospitalized with bacteremia who were on statins at admission had a significant reduction in in-hospital mortality ( $28 \%$ versus $6 \%$, $\mathrm{p}<0.002)$ [12]. In the multivariate analysis, after adjustment for confounding factors (including comorbid conditions, age, concurrent medications, site of infection, vital signs, and laboratory data) not being on a statin (odds ratio $7.6,95 \%$ confidence interval 1.01-57.5) was significantly associated with mortality. This prior research, combined with our results, supports the need for further research to examine the impact of statins in the treatment of infectious diseases. 
Table 2: Use versus non-use of statin by demographic and clinical characteristics*

\begin{tabular}{|c|c|c|c|}
\hline \multirow[t]{2}{*}{ Variable } & \multicolumn{2}{|c|}{ Statin } & \multirow[b]{2}{*}{ p-value } \\
\hline & Not on statin $(n=677)$ & On statin $(n=110)$ & \\
\hline Age, years $+/$ - standard deviation & $59.4+/-16.8$ & $66.3+/-12.3$ & $<0.001$ \\
\hline Men & $529(78)$ & $92(84)$ & 0.2 \\
\hline Nursing home resident & $5 I(8)$ & $3(3)$ & 0.06 \\
\hline Admitted through emergency department & $570(84)$ & $86(78)$ & 0.1 \\
\hline Admitted to intensive care within 24 hours & $135(20)$ & $19(17)$ & 0.5 \\
\hline \multicolumn{4}{|l|}{ Preexisting Comorbid Conditions } \\
\hline Diabetes Mellitus & $168(25)$ & $62(56)$ & $<0.001$ \\
\hline Alcoholism & $79(12)$ & $5(5)$ & 0.03 \\
\hline Current tobacco use & $217(32)$ & $18(16)$ & 0.001 \\
\hline Congestive heart failure & $99(15)$ & $24(22)$ & 0.05 \\
\hline History of stroke & $78(12)$ & $27(25)$ & $<0.001$ \\
\hline Chronic liver disease & $91(13)$ & $3(3)$ & 0.001 \\
\hline History of malignancy & $68(10)$ & $10(9)$ & 0.8 \\
\hline Renal insufficiency & $74(11)$ & $13(12)$ & 0.8 \\
\hline \multicolumn{4}{|c|}{ History, Physical, Laboratory, and Radiographic Data } \\
\hline Altered mental status & $76(11)$ & $9(8)$ & 0.3 \\
\hline Respiratory rate $>30$ per minute & $69(10)$ & $13(11)$ & 0.6 \\
\hline Systolic blood pressure $<90 \mathrm{mmHg}$ & $21(3)$ & $0(0)$ & 0.06 \\
\hline Heart rate $>125$ per minute & $96(14)$ & $9(8)$ & 0.09 \\
\hline Temperature $<95^{\circ}$ or $>104^{\circ} \mathrm{F}$ & $17(3)$ & $4(4)$ & 0.5 \\
\hline Arterial $\mathrm{pH}<7.35$ & $39(6)$ & $10(9)$ & 0.2 \\
\hline Arterial oxygenation saturation $<90 \%$ & $|5|(22)$ & $25(22)$ & 0.9 \\
\hline Hematocrit $<30 \%$ & $65(10)$ & $7(6)$ & 0.3 \\
\hline Serum blood urea nitrogen $>30 \mathrm{mg} / \mathrm{dL}$ & $146(22)$ & $22(20)$ & 0.7 \\
\hline Serum glucose $>250 \mathrm{mg} / \mathrm{dL}$ & $58(9)$ & $18(16)$ & 0.01 \\
\hline Serum sodium < $130 \mathrm{meq} / \mathrm{L}$ & $105(15)$ & $11(10)$ & 0.13 \\
\hline Pleural effusion on chest radiograph & $172(25)$ & $17(15)$ & 0.02 \\
\hline \multicolumn{4}{|l|}{ Pneumonia Severity Index } \\
\hline Class I-III & $357(53)$ & $52(47)$ & \\
\hline Class IV & $222(33)$ & $44(40)$ & \\
\hline Class V & $98(14)$ & $14(13)$ & 0.3 \\
\hline
\end{tabular}

* Data are presented as number (\%) or mean $+/$-standard deviation

Although our study was retrospective and subject to the recognized limitations of such studies, we carefully assembled our cohort from complete patient discharge data to avoid ascertainment bias. Additionally, during chart abstraction we encountered a very small amount $(<5 \%)$ of missing data. Our sample was predominantly men due to the inclusion of a VA hospital and it is possible, but unlikely, that women may have differential responsiveness to statins as compared to men. Also we are unable to assess factors such as duration of statin use, inpatient continuation of the statin, or the dose effect due to the design of this study. In addition we are unable to control for quality of health care that patients had prior to hospitalization. Further research is needed to examine these factors. Finally, as in any non-experimental study, we are unable to state conclusively that the prior outpatient use of statin is the cause of decreased mortality in this cohort. However, since patients on statins have numerous medi- cal conditions that are significantly associated with increased short-term morality we feel that we have good evidence that these medications may have beneficial effects for patients hospitalized with community-acquired pneumonia.

\section{Conclusion}

Our study finds that prior outpatient use of statins reduces mortality for patients hospitalized with communityacquired pneumonia. Our results add an additional potential benefit of statin use to the already compelling data for their use in patients with coronary artery disease, hypercholesterolemia, diabetes, and peripheral vascular disease. Additionally, patients with diabetes and vascular disease are at higher risk for either contracting pneumonia or dying from pneumonia when they do contract it. Further studies are needed to confirm the magnitude of the impact of statins, either pre-hospitalization or acute, on 


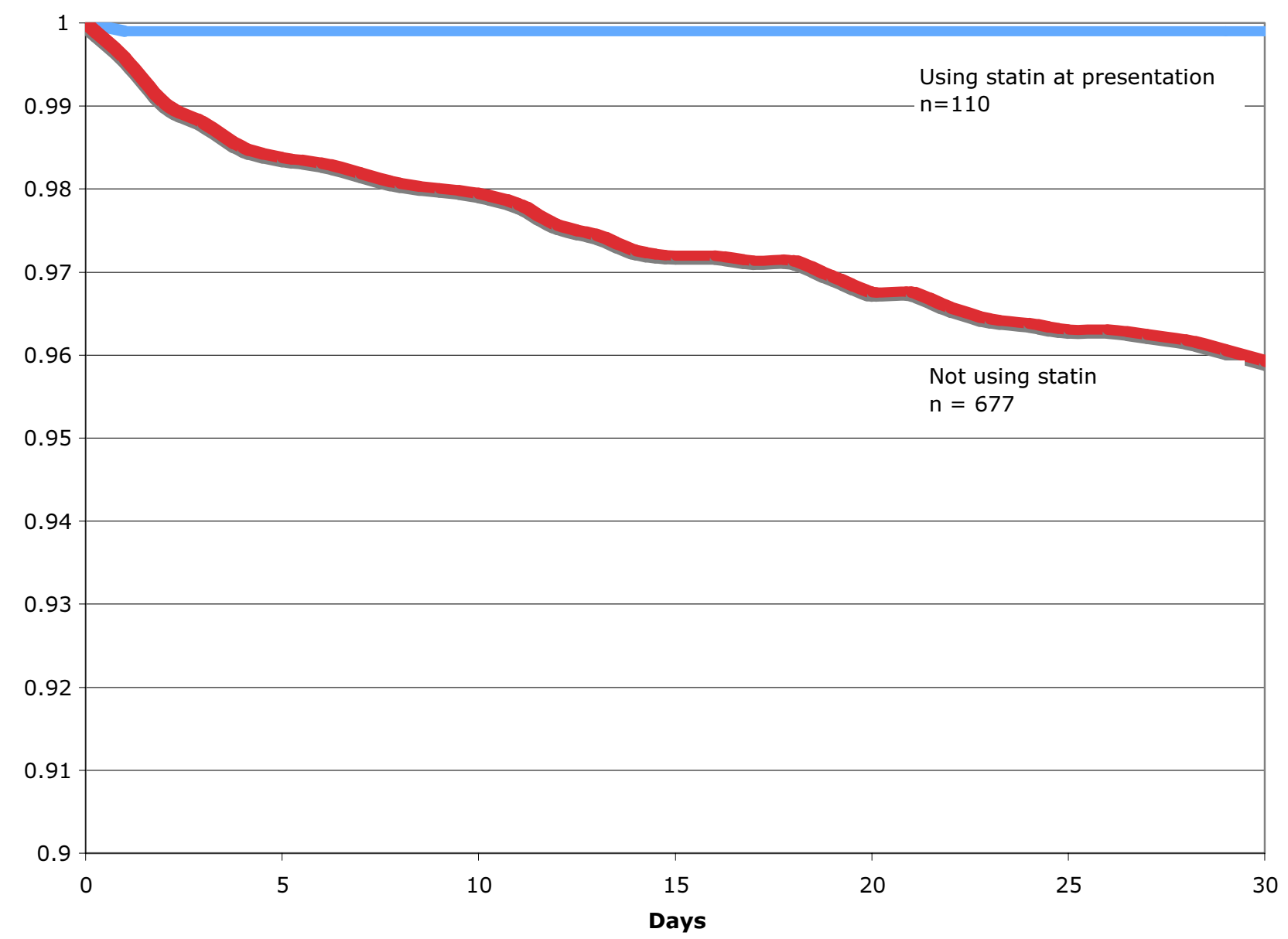

Figure I

Proportion of surviving patients hospitalized with community-acquired pneumonia by use of statin versus non-use after adjusting for the propensity score and other potential confounders $(p=0.00 \mathrm{I})$.

patients hospitalized with community-acquired pneumonia and to elucidate the mechanism by which they may work.

\section{Competing interests}

None of the authors, except for Dr. Anzueto, have any conflicts of interests to disclose regarding this paper. Dr. Anzueto is currently a consultant with Pfizer, OrthoMcNeil, and Bayer Pharma.

\section{Authors' contributions}

EMM originated and coordinated the study, obtained funding, contributed to the analysis of the data, and preparation of the paper.
MIR contributed to the design of the study, contributed to the analysis of the data, and preparation of the paper.

AA contributed to the design of the study and preparation of the paper.

JP contributed to the design of the study, contributed to the analysis of the data, and preparation of the paper.

\section{Acknowledgements}

Dr. Mortensen was supported by Howard Hughes Medical Institute facultystart up grant 00378-00I and a Department of Veteran Affairs Veterans Integrated Service Network 17 new faculty grant. Dr. Pugh was supported by Department of Veteran Affairs grant HFP98-002. This material is the result of work supported with resources and the use of facilities at the South Texas Veterans Health Care System. The funding agencies had no 
role in conducting the study, or role in the preparation, review, or approval of the manuscript

The views expressed in this article are those of the authors and do not necessarily represent the views of the Department of Veterans Affairs.

\section{References}

I. Hoyert DL, Arias E, Smith BL: Deaths: Final Data for 1999. Natl Vital Statistics Report 200 I, 49(8): I-I I3.

2. Gilbert K, Fine MJ: Assessing prognosis and predicting patient outcomes in community-acquired pneumonia. Seminars in Respiratory Infections 1994, 9(3): I40-152.

3. Jialal I, Stein D, Balis D, Grundy SM, Adams-Huet B, Devaraj S: Effect of hydroxymethyl glutaryl coenzyme a reductase inhibitor therapy on high sensitive C-reactive protein levels. Circulation 2001, I03( I 5): 1933-1935.

4. Musial J, Undas A, Gajewski P, Jankowski M, Sydor W, Szczeklik A: Anti-inflammatory effects of simvastatin in subjects with hypercholesterolemia. International Journal of Cardiology 2001, 77(2-3):247-253.

5. de Bont N, Netea MG, Rovers C, Smilde T, Demacker PN, van der Meer JW, Stalenhoef AF: LPS-induced cytokine production and expression of LPS-receptors by peripheral blood mononuclear cells of patients with familial hypercholesterolemia and the effect of HMG-CoA reductase inhibitors. Atherosclerosis 1998, I39(I): |47-I52.

6. Rosenson RS, Tangney CC, Casey LC: Inhibition of proinflammatory cytokine production by pravastatin. Lancet 1999, 353(9 I 57):983-984.

7. Ridker PM, Rifai N, Pfeffer MA, Sacks FM, Moye LA, Goldman S, Flaker $\mathrm{GC}$, Braunwald $\mathrm{E}$ : Inflammation, pravastatin, and the risk of coronary events after myocardial infarction in patients with average cholesterol levels. Cholesterol and Recurrent Events (CARE) Investigators. Circulation 1998, 98(9):839-844.

8. Strandberg TE, Vanhanen H, Tikkanen MJ: Effect of statins on Creactive protein in patients with coronary artery disease. Lancet 1999, 353(9147): I I8-II9.

9. Moussa K, Michie HJ, Cree IA, McCafferty AC, Winter JH, Dhillon DP, Stephens S, Brown RA: Phagocyte function and cytokine production in community acquired pneumonia. Thorax 1994, 49(2): |07-I|I.

10. Puren AJ, Feldman C, Savage N, Becker PJ, Smith C: Patterns of cytokine expression in community-acquired pneumonia. Chest 1995, I07(5): 1342-1349.

II. Bauer TT, Monton C, Torres A, Cabello H, Fillela X, Maldonado A, Nicolas JM, Zavala E: Comparison of systemic cytokine levels in patients with acute respiratory distress syndrome, severe pneumonia, and controls. Thorax 2000, 55(I):46-52.

12. Liappis AP, Kan VL, Rochester CG, Simon GL: The effect of statins on mortality in patients with bacteremia. Clinical Infectious Diseases 200I, 33(8): I352-1357.

13. Seraphin LM, Liappis AP, Kan VL, Simon GL: Increased incidence of lower extremity infections among diabetic patients receiving statins.: September and Decmeber 200I. 200I:76.

14. Meehan TP, Fine MJ, Krumholz HM, Scinto JD, Galusha DH, Mockalis JT, Weber GF, Petrillo MK, Houck PM, Fine JM: Quality of care, process, and outcomes in elderly patients with pneumonia. JAMA 1997, 278(23):2080-2084.

15. Niederman MS, Mandell LA, Anzueto A, Bass JB, Broughton WA, Campbell GD, Dean N, File T, Fine MJ, Gross PA, Martinez F, Marrie T], Plouffe JF, Ramirez J, Sarosi GA, Torres A, Wilson R, Yu VL: Guidelines for the management of adults with communityacquired pneumonia. Diagnosis, assessment of severity, antimicrobial therapy, and prevention. Am J Respir Crit Care Med 2001, I63(7): I730-I754.

16. Bartlett JG, Dowell SF, Mandell LA, File Jr TM, Musher DM, Fine MJ: Practice guidelines for the management of communityacquired pneumonia in adults. Infectious Diseases Society of America. Clin Infect Dis 2000, 3 I (2):347-382

17. Fine MJ, Auble TE, Yealy DM, Hanusa BH, Weissfeld LA, Singer DE, Coley CM, Marrie TJ, Kapoor WN: A prediction rule to identify low-risk patients with community-acquired pneumonia. $N$ Engl J Med 1997, 336(4):243-250.
18. Mortensen EM, Kapoor WN, Chang CC, Fine MJ: Assessment of mortality after long-term follow-up of patients with community-acquired pneumonia. Clin Infect Dis 2003, 37( I 2): I617-1624.

19. Mortensen EM, Coley CM, Singer DE, Marrie T], Obrosky DS Kapoor WN, Fine MJ: Causes of death for patients with community-acquired pneumonia: results from the Pneumonia Patient Outcomes Research Team cohort study. Arch Intern Med 2002, I 62(9): 1059-1064.

20. Stone RA, Obrosky DS, Singer DE, Kapoor WN, Fine MJ: Propensity score adjustment for pretreatment differences between hospitalized and ambulatory patients with communityacquired pneumonia. Pneumonia Patient Outcomes Research Team (PORT) Investigators. Med Care 1995, 33(4 Suppl):AS56-66.
Publish with Bio Med Central and every scientist can read your work free of charge

"BioMed Central will be the most significant development for disseminating the results of biomedical research in our lifetime. "

Sir Paul Nurse, Cancer Research UK

Your research papers will be:

- available free of charge to the entire biomedical community

- peer reviewed and published immediately upon acceptance

- cited in PubMed and archived on PubMed Central

- yours - you keep the copyright

Submit your manuscript here:

http://www.biomedcentral.com/info/publishing_adv.asp
BiolMedcentral 